\title{
Performance of Global Climate Model (GCMs) for Wind Data Analysis
}

\author{
Chutipat Foyhirun ${ }^{1, *}$, Duangrudee K.Kongkitkul ${ }^{2}$, and Chaiwat Ekkawatpanit ${ }^{2}$ \\ ${ }^{1} \mathrm{PhD}$ Student, Department of Civil Engineering, King Mongkut's University of Technology Thonburi, Thailand \\ ${ }^{2}$ Assistant Professor, Department of Civil Engineering, King Mongkut's University of Technology Thonburi, Thailand
}

\begin{abstract}
The surface wind speed is an important climate variable for study of ocean wave energy and coastal erosion. The wind speed and wave height variations are caused by global warming. In the future, climate change impacts on changes of direction and wind speed which affect on wave height and wave period. The global climate model (GCMs) were developed by various institutions so each GCM has different GCM output. Then, the aim of this study is to evaluation the performance of GCMs for wind speed analysis in the area of Gulf of Thailand and Andaman Sea. In this study, the daily wind speed data was analyzed with a total of 15 GCMs and daily wind speed data of NCEP-NCAR was used as observation data to compare with wind speed data from GCMs over the period 1986-2005 (20 years). Moreover, the wind speed data was evaluated by efficiency coefficient which are root mean square error (RMSE) and mean absolute error (MAE). It was found tht MRI-CGCM3, GFDL-ESM2M, IPSL-CM5A-LR, and IPSL-CM5A-MR are consistent with the most of observation data from NCEP-NCAR.
\end{abstract}

\section{Introduction}

Nowadays, the renewable energy are applied to solve the problem of reducing greenhouse gas emission. Wave energy, which is one of renewable energy, is interesting and less developed than other renewable energy. There are many researches that study the evaluation of global wave energy resources [1-2]. Asia and Australasia regions receive the largest quantity of wave energy. Central America and the Mediterranean Sea and Atlantic Archipelagos region receive the slightest quantity of wave energy due to their mid-latitude position. The total global wave energy potential is around $32 \mathrm{PWh} /$ year [3] and the wave energy in Southeast Asian is around $<5-20$ $\mathrm{kW} / \mathrm{m}$.

Wave energy is an energy which is transferred by waves. When the more strong the waves, the more able it is to generate energy. It corresponds with the studies of future wave climate projection [4-5], which have shown an increase in wave height because wind speed increase. So, the wind speed is a major factor affecting high or low wave height. Wave energy has high or low dependent on wave height and wave energy period. Moreover, the study trends of the global wind speed found that the global oceanic sea surface wind speeds have rate increase of $3.35 \mathrm{~cm} / \mathrm{s} / \mathrm{yr}$ and the trend of increasing wind speed over the Southern Ocean is greater than over the Northern Ocean [6]. In the future, wave height and wave period may be affected from climate change on wind speed.

In present, there is wide selection of climate models available to provide projections of future climate change.
GCMs are employed for assessment regional or local issues. Each GCMs simulates the earth's climate with different climate parameters, initial and boundary conditions, resolution and model structure. GCMs has different results. This is problem for selecting appropriate GCMs with region from the large number of GCMs available. Therefore, the aim of this study is to evaluate the performance of GCMs for wind speed analysis in the area of Gulf of Thailand and Andaman Sea.

\section{Data and method}

This section will mention the data and method of this study. The evaluation of the performance of the GCMs requires the comparison with historical observation. The data used to evaluate the performance of GCMs was taken from the National Centers for Environmental Prediction-National Center for Atmospheric Research (NCEP-NCAR). NCEP-NCAR has been widely used by climate modeling communities. NCEP-NCAR reanalysis of daily wind speed at $10\left(U_{10}\right)$ meter was used in this study. The GCMs outputs received from the Coupled Model Intercomparison Project phase 5 (CMIP5). Table 1 shows a list of CMIP5 GCMs. The time period 19862005 was selected as the historical period.

The study area was separated as Gulf of Thailand (GOT) and Andaman Sea (AS). GOT is located from $6^{\circ} \mathrm{N}$ to $13^{\circ} 30^{\prime} \mathrm{N}$ latitude and $99^{\circ} \mathrm{E}$ to $104^{\circ} \mathrm{E}$ longitude. AS is located from $4^{\circ} \mathrm{N}$ to $20^{\circ} \mathrm{N}$ latitude and $92^{\circ} \mathrm{E}$ to $100^{\circ} \mathrm{E}$ longitude. In this study, the wind speed

* Corresponding author: chutipat.971@mail.kmutt.ac.th 
data of observation and GCMs were compared as grid point, which is weather station of Thai Meteorological Department (TMD). The weather stations of TMD were chosen to be a shoreline or nearshore location [7-8]. The 14 and 5 weather stations of TMD were used in GOT and AS respectively, as show in Fig. 1.

The root mean squared error (RMSE) and mean absolute error (MAE) are two most commonly used metrics for measuring the performance accuracy of data or model. RMSE is the square root of the squared differences between observation and simulation, as show in Equation (1). MAE, calculate by Equation (2), is used to estimate the difference between two continuous variables. Moreover, the standard deviation (SD) is calculated in each station of observation data in order to verify the accuracy of GCMs data. It the GCM data is within the SD range, then the GCM data is effective to be used.

$$
\begin{gathered}
R M S E=\sqrt{\frac{1}{N} \sum_{i=1}^{N}\left(P_{i}-O_{i}\right)^{2}} \\
M A E=\frac{1}{N} \sum_{i=1}^{N}\left|P_{i}-O_{i}\right|
\end{gathered}
$$

where $P_{i}$ is the simulation value

$O_{i}$ is the observation value

$N$ is the number of data

\begin{tabular}{|c|c|c|}
\hline Model & Country & $\begin{array}{c}\text { Resolution } \\
\text { (lat x lon) }\end{array}$ \\
\hline $\begin{array}{c}\text { BCC- } \\
\text { CSM1-1 }\end{array}$ & Beijing climate center/China & $2.8^{\circ} \times 2.8^{\circ}$ \\
\hline $\begin{array}{c}\text { BCC- } \\
\text { CSM1-1M }\end{array}$ & Beijing climate center/China & $1.12^{\circ} \times 1.12^{\circ}$ \\
\hline BNU-ESM & $\begin{array}{l}\text { College of global change and } \\
\text { earth system science/China }\end{array}$ & $2.8^{\circ} \times 2.8^{\circ}$ \\
\hline CanESM2 & $\begin{array}{c}\text { Canadian center for climate } \\
\text { modelling and } \\
\text { analysis/Canada }\end{array}$ & $2.8^{\circ} \times 2.8^{\circ}$ \\
\hline $\begin{array}{l}\text { CNRM- } \\
\text { CM5 }\end{array}$ & $\begin{array}{l}\text { Center nation de recherches } \\
\text { meteorologiques/France }\end{array}$ & $1.4^{\circ} \times 1.4^{\circ}$ \\
\hline $\begin{array}{l}\text { CSIRO- } \\
\text { Mk3.6.0 }\end{array}$ & CSIRO-QCCCE/Australia & $1.9^{\circ} \times 1.9^{\circ}$ \\
\hline $\begin{array}{l}\text { GFDL- } \\
\text { CM3 }\end{array}$ & $\begin{array}{l}\text { NOAA geophysical fluid } \\
\text { dynamics laboratory/USA }\end{array}$ & $2.0^{\circ} \times 2.5^{\circ}$ \\
\hline $\begin{array}{l}\text { GFDL- } \\
\text { ESM2G }\end{array}$ & $\begin{array}{l}\text { NOAA geophysical fluid } \\
\text { dynamics laboratory/USA }\end{array}$ & $2.0^{\circ} \times 2.5^{\circ}$ \\
\hline $\begin{array}{l}\text { GFDL- } \\
\text { ESM2M }\end{array}$ & $\begin{array}{l}\text { NOAA geophysical fluid } \\
\text { dynamics laboratory/USA }\end{array}$ & $2.0^{\circ} \times 2.5^{\circ}$ \\
\hline $\begin{array}{c}\text { IPSL- } \\
\text { CM5A-LR }\end{array}$ & $\begin{array}{l}\text { Institute pier-simon } \\
\text { laplace/France }\end{array}$ & $1.9^{\circ} \times 3.75^{\circ}$ \\
\hline $\begin{array}{c}\text { IPSL- } \\
\text { CM5A-MR } \\
\end{array}$ & $\begin{array}{c}\text { Institute pier-simon } \\
\text { laplace/France }\end{array}$ & $1.25^{\circ} \times 2.5^{\circ}$ \\
\hline MIROC5 & MIROC/Japan & $1.4^{\circ} \times 1.4^{\circ}$ \\
\hline $\begin{array}{l}\text { MIROC- } \\
\text { ESM }\end{array}$ & MIROC/Japan & $2.8^{\circ} \times 2.8^{\circ}$ \\
\hline $\begin{array}{l}\text { MIROC- } \\
\text { ESM- } \\
\text { CHEM } \\
\end{array}$ & MIROC/Japan & $2.8^{\circ} \times 2.8^{\circ}$ \\
\hline $\begin{array}{c}\text { MRI- } \\
\text { CGCM3 }\end{array}$ & $\begin{array}{c}\text { Meteorological research } \\
\text { institute/Japan }\end{array}$ & $1.1^{\circ} \times 1.1^{\circ}$ \\
\hline
\end{tabular}

Table 1. List of CMIP5 GCMs.

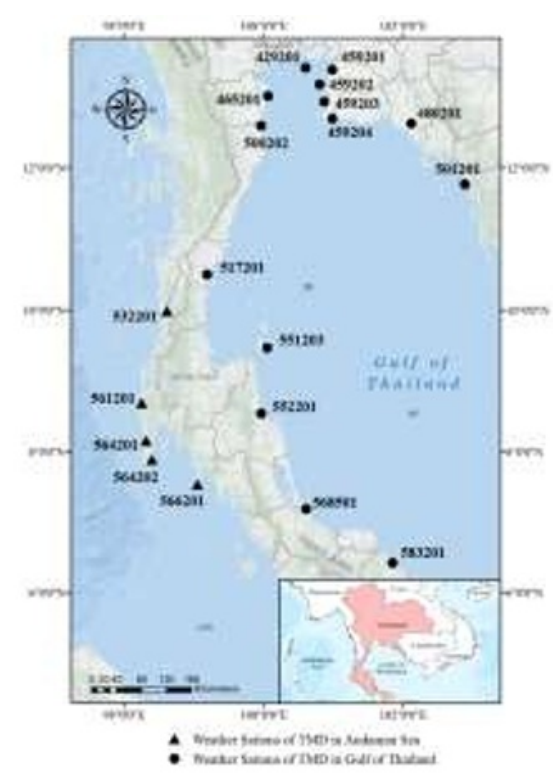

Fig. 1. Weather station of TMD in area of GOT and AS.

\section{Results and discussions}

In this study, the wind speed data from all of 15 GCMs were compared with observed data from NCEP-NCAR in historical period (1986-2005). This comparison of wind speed would be shown as value of RMSE and MAE. Moreover, the wind speed from GCMs were compared with SD range of observation.

Fourteen weather stations of TMD in the area GOT were used as locations of grid point in order to compare between observation and GCM. The 14 weather stations of TMD include 429201, 459201, 459202, 459203, 459204, 501201, 480201, 552201, 568501, 583201, 465201, 500202, 517201, and 551203. Table2 and 3 show the value of RMSE and MAE of each GCMs at various weather station of TMD in the area GOT, respectively. Table 2 and 3 do not show all 14 weather stations of TMD because some weather stations of TMD are located in the same grid point, resulting in the same value. The results found that the RMSE and MAE values were both high and low. In this study, RMSE and MAE were considered at low value. Considering the RMSE and MAE values of all 14 weather stations of TMD, GMs of five sequences which had the lowest values of RMSE and MAE were MIROC5, MIROC-ESM, MIROC-ESM-CHEM, GFDL-ESM2M, and MRICGCM3. Besides, Fig. 2 shows the comparison between wind speed of GCMs with wind speed of observation from NCEP-NCAR in GOT. The results found that wind speed line of MRI-CGCM3 is similar to the observation data and close value with observation data which is in a range of SD. Wind speed of GFDL-ESM2M has a shape similar to observation data but it is higher value than observation data. While, MIROC5 and MIROC-ESM is lower value than observation data and below a quarter of SD. The wind speed of other GCMs id higher value than observation data and they have not a shape similar to observation data.

Five weather stations of TMD in the area AS were used as location of grid point for evaluation of GCMs 
performance. The 5 weather stations of TMD include 532201, 564201, 564202, 566201, and 561201. Table 4 and 5 show the value of RMSE and MAE of each GCMs at various weather station of TMD in the area AS, respectively. The results found that the RMSE and MAE values of AS were quite higher than Gulf of Thailand. The RMSE and MAE was considered at low value. MRICGCM3, IPSL-CM5A-LR, IPSL-CM5A-MR, and BNUESM show the lowest the RMSE and MAE value. Fig. 3 shows the comparison wind speed in AS between GCMs and observation data from NCEP-NCAR. The results found that line of MRI-CGCM3, IPSL-CM5A-LR, IPSL-CM5A-MR, and BNU-ESM are near the observation line which is in a range of SD. So, the similarity of GCMs with observation data was taken consideration, it found that MRI-CGCM3 is the most of similar to observation data and followed by IPSLCM5A-LR and IPSL-CM5A-MR. The wind speed of other GCMs is both higher and lower value than observation data and not range of SD.

The results of evaluation of GCMs performance by considering the RMSE and MAE value in GOT and AS shown that MRI-CGCM3 is low values of RMSE and MAE. The comparison wind speed between GCMs with observation data, which is in a SD range, in GOT and AS found that MRI-CGCM3 is the most similar feature to observation data and is in a range of SD. While, the wind speed of GFDL-ESM2M and IPSL-CM5A-LR and IPAS-CM5A-MR are similar to observation in GOT and AS, respectively. The GCMs selection that provide assessment results in accordance with observation may select 3-5 GCMs for climate change studies. Therefore, MRI-CGCM3, GFDL-ESM2M, IPSL-CM5A-LR, and IPSL-CM5A-MR were selected for evaluation wave energy in the future.

Table 2. RMSE of each GCMs at various weather station in GOT.

\begin{tabular}{|c|c|c|c|c|c|c|c|c|c|c|}
\hline \multirow{2}{*}{ GCMs } & \multicolumn{9}{|c|}{ Weather Station of TMD } \\
\cline { 2 - 11 } & 429201 & 501201 & 480201 & 552201 & 568501 & 583201 & 465201 & 500202 & 517201 & 551203 \\
\hline BCC-CSM1-1 & 2.591 & 2.715 & 3.158 & 2.427 & 2.427 & 1.404 & 2.591 & 2.591 & 2.292 & 2.532 \\
\hline BCC-CSM1-1M & 3.257 & 3.664 & 4.649 & 1.585 & 1.979 & 1.501 & 1.576 & 1.383 & 2.501 & 2.519 \\
\hline BNU-ESM & 2.346 & 2.609 & 2.445 & 2.348 & 2.348 & 1.273 & 2.346 & 2.346 & 2.467 & 2.641 \\
\hline CanESM2 & 1.543 & 3.306 & 1.975 & 1.936 & 1.936 & 1.010 & 1.543 & 1.543 & 2.559 & 2.762 \\
\hline CNRM-CM5 & 2.249 & 2.992 & 4.230 & 1.940 & 1.809 & 0.867 & 3.207 & 3.207 & 2.412 & 2.595 \\
\hline CSIRO-Mk3.6.0 & 1.867 & 3.031 & 3.073 & 1.925 & 2.752 & 1.161 & 1.867 & 1.867 & 3.135 & 2.399 \\
\hline GFDL-CM3 & 1.816 & 2.667 & 3.618 & 2.354 & 2.354 & 1.312 & 2.214 & 2.214 & 2.355 & 2.511 \\
\hline GFDL-ESM2G & 2.244 & 3.877 & 5.221 & 2.541 & 2.541 & 1.237 & 2.712 & 2.712 & 2.301 & 2.507 \\
\hline GFDL-ESM2M & 1.469 & 3.581 & 4.833 & 2.870 & 2.870 & 0.985 & 1.635 & 1.635 & 2.468 & 2.621 \\
\hline IPSL-CM5A-LR & 1.939 & 2.734 & 3.619 & 2.362 & 2.791 & 1.130 & 1.939 & 1.939 & 2.403 & 2.397 \\
\hline IPSL-CM5A-MR & 3.415 & 2.196 & 3.390 & 2.843 & 1.581 & 2.106 & 3.415 & 1.329 & 2.736 & 2.419 \\
\hline MIROC5 & 1.091 & 2.530 & 1.263 & 2.110 & 1.834 & 0.873 & 1.337 & 1.337 & 3.609 & 4.023 \\
\hline MIROC-ESM & 1.370 & 2.564 & 1.740 & 1.651 & 1.651 & 1.228 & 1.370 & 1.370 & 4.284 & 3.424 \\
\hline MIROC-ESM-CHEM & 1.390 & 2.598 & 1.730 & 1.647 & 1.647 & 1.232 & 1.390 & 1.390 & 4.281 & 3.431 \\
\hline MRI-CGCM3 & 2.432 & 3.749 & 4.996 & 1.490 & 1.330 & 0.726 & 0.844 & 0.835 & 2.567 & 3.168 \\
\hline
\end{tabular}

Table 3. MAE of each GCMs at various weather station in GOT.

\begin{tabular}{|c|c|c|c|c|c|c|c|c|c|c|}
\hline \multirow{2}{*}{ GCMs } & \multicolumn{9}{|c|}{ Weather Station of TMD } \\
\cline { 2 - 12 } & 429201 & 501201 & 480201 & 552201 & 568501 & 583201 & 465201 & 500202 & 517201 & 551203 \\
\hline BCC-CSM1-1 & 2.133 & 2.182 & 2.702 & 1.955 & 1.955 & 1.198 & 2.133 & 2.133 & 1.817 & 2.071 \\
\hline BCC-CSM1-1M & 2.843 & 2.882 & 4.025 & 1.280 & 1.608 & 1.312 & 1.283 & 1.134 & 1.987 & 2.021 \\
\hline BNU-ESM & 1.878 & 2.036 & 2.025 & 1.876 & 1.876 & 1.035 & 1.878 & 1.878 & 1.965 & 2.110 \\
\hline CanESM2 & 1.193 & 2.620 & 1.505 & 1.532 & 1.532 & 0.740 & 1.193 & 1.193 & 2.030 & 2.197 \\
\hline CNRM-CM5 & 1.712 & 2.303 & 3.552 & 1.517 & 1.417 & 0.677 & 2.578 & 2.578 & 1.919 & 2.074 \\
\hline CSIRO-Mk3.6.0 & 1.520 & 2.490 & 2.522 & 1.561 & 2.290 & 0.946 & 1.520 & 1.520 & 2.550 & 1.908 \\
\hline GFDL-CM3 & 1.465 & 2.094 & 3.114 & 1.893 & 1.893 & 1.081 & 1.819 & 1.819 & 1.888 & 1.984 \\
\hline GFDL-ESM2G & 1.883 & 3.186 & 4.601 & 2.117 & 2.117 & 1.063 & 2.312 & 2.312 & 1.810 & 1.977 \\
\hline GFDL-ESM2M & 1.190 & 2.909 & 4.225 & 2.344 & 2.344 & 0.811 & 1.328 & 1.328 & 1.959 & 2.065 \\
\hline IPSL-CM5A-LR & 1.552 & 2.109 & 2.977 & 1.901 & 2.260 & 0.914 & 1.552 & 1.552 & 1.912 & 1.900 \\
\hline IPSL-CM5A-MR & 2.792 & 1.719 & 2.768 & 2.303 & 1.266 & 1.786 & 2.792 & 1.047 & 2.209 & 1.908 \\
\hline MIROC5 & 0.903 & 2.030 & 1.026 & 1.752 & 1.481 & 0.692 & 1.173 & 1.173 & 3.058 & 3.392 \\
\hline MIROC-ESM & 1.211 & 2.064 & 1.537 & 1.324 & 1.324 & 1.024 & 1.211 & 1.211 & 3.813 & 2.768 \\
\hline MIROC-ESM-CHEM & 1.232 & 2.104 & 1.527 & 1.312 & 1.312 & 1.029 & 1.232 & 1.232 & 3.807 & 2.763 \\
\hline MRI-CGCM3 & 2.098 & 2.936 & 4.293 & 1.174 & 1.061 & 0.588 & 0.667 & 0.660 & 2.059 & 2.558 \\
\hline
\end{tabular}



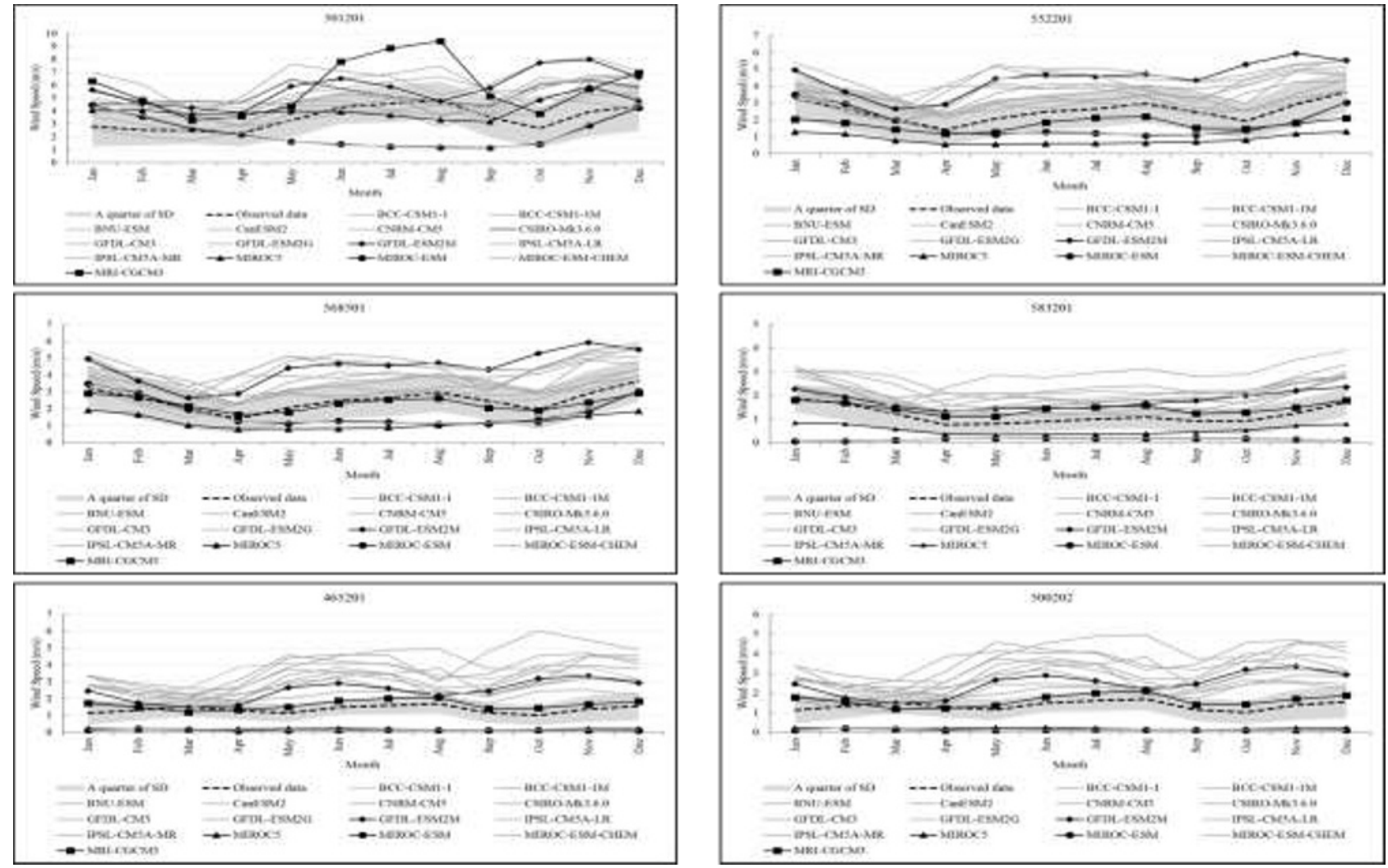

Fig. 2. Comparison of wind speed between observation and GCM at various weather stations in GOT.

Table 4. RMSE of each GCMs at various weather station in AS.

\begin{tabular}{|c|c|c|c|c|c|}
\hline \multirow{2}{*}{ GCMs } & \multicolumn{5}{|c|}{ Weather Station of TMD } \\
\cline { 2 - 6 } & 532201 & 564201 & 564202 & 566201 & 561201 \\
\hline $\begin{array}{c}\text { BCC- } \\
\text { CSM1-1 }\end{array}$ & 2.887 & 3.188 & 3.188 & 2.531 & 3.208 \\
\hline $\begin{array}{c}\text { BCC- } \\
\text { CSM1-1M }\end{array}$ & 2.622 & 2.817 & 2.817 & 2.427 & 2.660 \\
\hline BNU-ESM & 2.811 & 2.659 & 2.659 & 2.530 & 2.901 \\
\hline CanESM2 & 3.234 & 2.934 & 2.934 & 2.967 & 2.982 \\
\hline $\begin{array}{c}\text { CNRM- } \\
\text { CM5 }\end{array}$ & 2.882 & 3.112 & 3.112 & 2.759 & 3.236 \\
\hline $\begin{array}{c}\text { CSIRO- } \\
\text { Mk3.6.0 }\end{array}$ & 3.079 & 2.910 & 2.910 & 2.910 & 3.079 \\
\hline $\begin{array}{c}\text { GFDL- } \\
\text { CM3 }\end{array}$ & 2.817 & 2.862 & 2.862 & 2.544 & 2.994 \\
\hline $\begin{array}{c}\text { GFDL- } \\
\text { ESM2G }\end{array}$ & 3.645 & 3.307 & 3.307 & 2.385 & 3.237 \\
\hline $\begin{array}{c}\text { GFDL- } \\
\text { ESM2M }\end{array}$ & 3.389 & 3.090 & 3.090 & 2.584 & 3.140 \\
\hline $\begin{array}{c}\text { IPSL- } \\
\text { CM5A-LR }\end{array}$ & 2.653 & 2.588 & 2.588 & 2.588 & 2.653 \\
\hline $\begin{array}{c}\text { IPSL- } \\
\text { CM5A- } \\
\text { MR }\end{array}$ & 2.969 & 2.608 & 2.608 & 2.499 & 2.612 \\
\hline $\begin{array}{c}\text { MIROC5 } \\
\text { MIROC- } \\
\text { ESM }\end{array}$ & 4.437 & 2.685 & 2.685 & 3.183 & 2.889 \\
\hline $\begin{array}{c}\text { MIROC- } \\
\text { ESM- } \\
\text { CHEM }\end{array}$ & 5.121 & 2.937 & 2.937 & 3.616 & 3.426 \\
\hline $\begin{array}{c}\text { MRI- } \\
\text { CGCM3 }\end{array}$ & 2.547 & 2.767 & 2.767 & 2.480 & 2.519 \\
\hline
\end{tabular}

Table 5. MAE of each GCMs at various weather station in AS.

\begin{tabular}{|c|c|c|c|c|c|}
\hline \multirow{2}{*}{ GCMs } & \multicolumn{5}{|c|}{ Weather Station of TMD } \\
\cline { 2 - 6 } & 532201 & 564201 & 564202 & 566201 & 561201 \\
\hline $\begin{array}{c}\text { BCC- } \\
\text { CSM1-1 }\end{array}$ & 2.293 & 2.488 & 2.488 & 2.042 & 2.547 \\
\hline $\begin{array}{c}\text { BCC- } \\
\text { CSM1-1M }\end{array}$ & 2.077 & 2.245 & 2.245 & 1.951 & 2.111 \\
\hline BNU-ESM & 2.230 & 2.120 & 2.120 & 2.020 & 2.335 \\
\hline CanESM2 & 2.589 & 2.335 & 2.335 & 2.401 & 2.391 \\
\hline $\begin{array}{c}\text { CNRM- } \\
\text { CM5 }\end{array}$ & 2.292 & 2.470 & 2.470 & 2.191 & 2.595 \\
\hline $\begin{array}{c}\text { CSIRO- } \\
\text { Mk3.6.0 }\end{array}$ & 2.459 & 2.318 & 2.318 & 2.318 & 2.459 \\
\hline $\begin{array}{c}\text { GFDL- } \\
\text { CM3 }\end{array}$ & 2.238 & 2.271 & 2.271 & 2.024 & 2.393 \\
\hline $\begin{array}{c}\text { GFDL- } \\
\text { ESM2G }\end{array}$ & 2.917 & 2.641 & 2.641 & 1.919 & 2.587 \\
\hline $\begin{array}{c}\text { GFDL- } \\
\text { ESM2M }\end{array}$ & 2.678 & 2.454 & 2.454 & 2.069 & 2.485 \\
\hline $\begin{array}{c}\text { IPSL- } \\
\text { CM5A-LR }\end{array}$ & 2.103 & 2.087 & 2.087 & 2.087 & 2.103 \\
\hline $\begin{array}{c}\text { IPSL- } \\
\text { CM5A- } \\
\text { MR }\end{array}$ & 2.365 & 2.101 & 2.101 & 2.003 & 2.070 \\
\hline \begin{tabular}{c} 
MIROC5 \\
\hline $\begin{array}{c}\text { MIROC- } \\
\text { ESM }\end{array}$
\end{tabular} & 3.809 & 2.155 & 2.155 & 2.614 & 2.294 \\
\hline $\begin{array}{c}\text { MIROC- } \\
\text { ESM- } \\
\text { CHEM }\end{array}$ & 4.569 & 2.360 & 2.360 & 3.028 & 2.768 \\
\hline $\begin{array}{c}\text { MRI- } \\
\text { CGCM3 }\end{array}$ & 2.020 & 2.200 & 2.200 & 1.992 & 2.000 \\
\hline
\end{tabular}




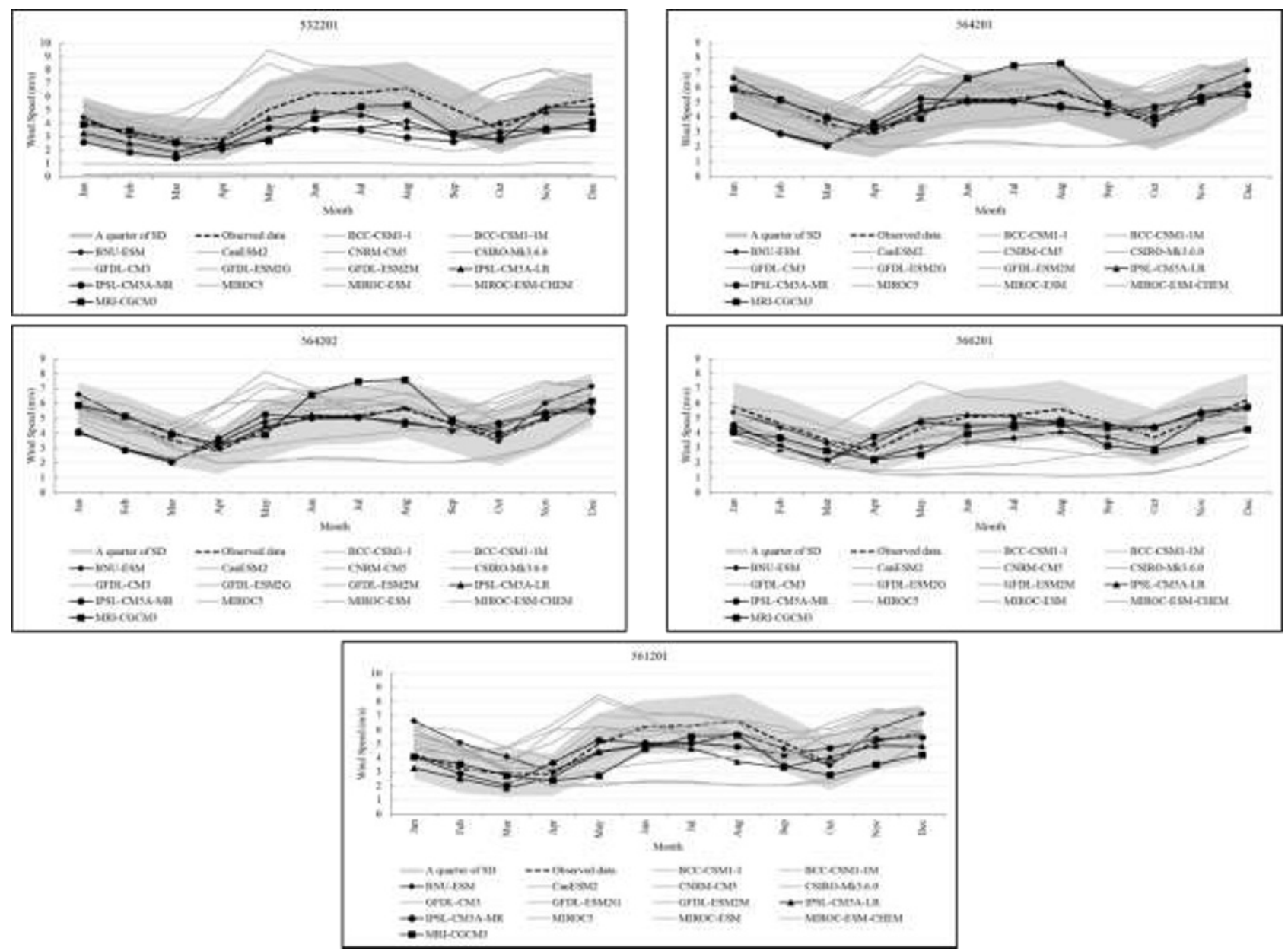

Fig. 3. Comparison of wind speed between observation and GCM at various weather stations in Andaman Sea.

\section{Conclusion}

This study is the evaluation of the performance of GCMs for wind speed analysis in the area of Gulf of Thailand and Andaman Sea. The wind speed of 15 GCMs were compared with observation data from NCEP-NCAR in historical period 1986-2005 at various weather stations of TMD. RMSE and MAE were used to consider the performance of GCMs. The results of this study indicate that MRI-CGCM3 shows the best performance to study the climate change which impact on wave energy in the future. MRI-CGCM3 had low value of RMSE and MAE and the wind speed data was similar to observation data from NCEP-NCAR. However, the GCMs selection that provide reliable assessment results of studies may choose 3-5 GCMs for climate change studies. So, MRICGCM3, GFDL-ESM2M, IPSL-CM5A-LR, and IPSLCM5A-MR were selected for evaluation wave energy in the future. Moreover, wind speed data of GCMs in this study may need to do the bias correction or downscaling in order to receive the accuracy data before using study of wave energy in the future.

The authors would like to thank civil engineering department, faculty of engineering, King Mongkut's University of Technology Thonburi for financial support.

\section{References}

1. A.M. Cornett, RENEW ENERG, 1-9 (2008)

2. B.G. Reguero, C. Vidal, M. Mendez, R. Minguez, I. Losada, Oceans 2011 IEEE-Spain, 1-7 (2011)

3. G. Mork, S. Barstow, A.K. Kabuth, M.T. Pontes, OMAE2010 (ASME), (2010)

4. N. Mori, T. Yasuda, H. Mase, T. Tom, T. Oku, HRL, 4, 15-19 (2010)

5. A. Semedo, R. Weisse, A. Behrens, A. Sterl, L. Bengtsson, H. Gunther, JCLI, 26, 8269-8288 (2013)

6. C.W. Zheng, J. Pan, C.Y. Li, OCEAN COAST MANAGE, 129, 15-24 (2016)

7. C. Foyhirun, D. Kositkittiwong, C. Ekkawatpanit, AWTEC (2016)

8. W. Kompor, C. Ekkawatpanit, D. Kositkittiwong, AWTEC (2016) 